\title{
Increasing the employment rate for people with longer-term mental health problems
}

\author{
Miles Rinaldi, ${ }^{1}$ Tatiana Montibeller, ${ }^{1}$ Rachel Perkins ${ }^{1}$
}

The Psychiatrist (2011), 35, 339-343, doi: 10.1192/pb.bp.109.028050

${ }^{1}$ South West London and St George's Mental Health NHS Trust

Correspondence to Miles Rinaldi (miles.rinaldi@swlstg-tr.nhs.uk)

First received 7 Sep 2009, final revision 2 Nov 2010, accepted 10 Dec 2010
Aims and method To examine the effects of implementing the individual placement and support (IPS) approach within four community mental health teams (CMHTs). Demographic, clinical and vocational data were collected through a repeated crosssectional survey. Additionally, a service user experience survey was conducted.

Results The IPS approach appears to have a significant effect on the employment rates of service users; a higher proportion felt able to return to employment and a smaller proportion believed they were unable to work because of their mental health problems. Employment rates for service users appear to be independent of general employment rates.

Clinical implications Implementing IPS appears to increase the employment rates in CMHTs resulting in increased service user expectations of being able to return to work.

Declaration of interest None.
People with mental health problems often consider employment as a yardstick to their recovery. ${ }^{1,2}$ However, they experience low rates of employment, especially those using secondary mental health services, of whom typically between 4 and $16 \%$ are employed. ${ }^{3-5}$

The low priority given to employment by mental health professionals combined with the low expectations of people with mental health problems themselves in being able to gain employment may partly account for these low employment rates. ${ }^{6-8}$ These low expectations are reinforced by the attitudes of an overwhelming number of professionals, with only $8 \%$ of community mental health teams' (CMHTs) case notes addressing vocational needs ${ }^{9}$ and mental health professionals holding the belief that the majority of people on their case-loads are only capable of sheltered or voluntary work. $^{10}$ Yet, surveys in England show that people with mental health problems who use mental health services would like help with gaining employment: ${ }^{11}$ supporting people to do the things they want to do is critical if we are to successfully enable recovery, independence and inclusion.

The individual placement and support (IPS) approach is an evidence-based practice and has repeatedly been shown to be more effective than other vocational rehabilitation approaches in enabling people with severe mental health problems to gain employment. ${ }^{12-14}$ It has been recommended by the Department of Health ${ }^{15,16}$ and the National Institute for Health and Clinical Excellence. ${ }^{17,18}$ The South West London and St George's Mental Health NHS Trust has successfully implemented the IPS approach to high fidelity within CMHTs ${ }^{14,19}$ and early intervention teams for young people with a first episode of psychosis ${ }^{20,21}$ and evaluated the lessons learnt to implementing this evidence-based practice. ${ }^{8,22}$ This paper reports the effects of implementing the IPS approach within four CMHTs in London and the associated effect on the employment rates across these teams. In addition, service user experience is reported in relation to met and unmet need with finding work and the perception of whether service users felt they were unable to work because of their mental health problems.

\section{Method}

\section{The IPS service}

In February 2004, the IPS approach was implemented in the four CMHTs in the London borough of Merton, with three employment specialists working across these teams. By January 2005 there was a full-time employment specialist in each CMHT and an independent assessment identified that high-fidelity IPS was being delivered. ${ }^{17}$

\section{Cross-sectional survey}

Data concerning the vocational status of people with longerterm mental health problems during the 10 years from 1990 to 1999 were collected via a cross-sectional survey of adults using secondary mental health services in Merton. Basic demographic, psychiatric, service usage, accommodation and vocational information was collected by care coordinators on 1 April each year for all service users who had experienced their first contact with psychiatric services at 
least 2 years previously. Vocational status was reported in five categories: open employment, sheltered work, voluntary work, mainstream education and unemployed. Open employment included ordinary, existing, full-time, parttime or casual work gained in open competition. It did not include jobs created under special employment schemes for people with mental health problems.

On 1 December 2003 the cross-sectional survey was repeated using the same survey tool, criteria and method previously used within the service during the 1990s. The survey was repeated thereafter on 1 December each year through to 2006 .

General employment rates for Merton were obtained from the Office for National Statistics. ${ }^{23}$

\section{Service user survey}

In the last quarter of 2006, a questionnaire survey was conducted in Merton to find out what service users thought about the care they received from mental health services. Using the Healthcare Commission's community mental health service users' survey instrument, ${ }^{11}$ care coordinators were asked to distribute the questionnaire to all service users, encouraging them to complete and return it anonymously in a 'free-post' envelope supplied. A section of the survey asked service users to rate the support they have received within the community. One question in this section asked: 'In the past 12-months, have you received any help with finding work?' There were four response options: 'Yes', 'No, but I would have liked some', 'I did not need any help' and 'I cannot work because of my mental health problems'.

\section{Results}

\section{Employment rates}

Table 1 shows that there was a mean of 569 longer-term service users in Merton in contact with local mental health services each year between 1990 and 1999, over half of whom had a diagnosis of schizophrenia. For the years 20032006 there was a mean of 728 longer-term service users in contact with mental health services, over half of whom had a diagnosis of schizophrenia.

Table 2 shows general employment rates in Merton from 1994 to 2006 (data from the Labour Force Survey ${ }^{23}$ were only available from 1994) and employment rates for longer-term service users from 1990 to 1999 and 2003 to 2006 (the two periods when our cross-sectional survey was carried out). Between 1990 and 1999 the employment rate among service users with longer-term mental health problems decreased significantly $\left(\chi^{2}=18.9, \quad\right.$ d.f. $=1$, $P<0.0001)$. Employment rates decreased from $25.7 \%$ in 1990 to $19.2 \%$ in 1993 and it can be assumed that this downward trend was also found in the general employment rate in Merton as the country was in recession. However, April 1993 is regarded as when the country came out of the last recession ${ }^{24}$ and the general employment rate in Merton grew from $76.8 \%$ in 1994 to $79.3 \%$ by 1999. By contrast, the employment rates for longer-term service users continued to decrease, from $14.2 \%$ in 1994 to $13.6 \%$ by 1999 . The employment rate also significantly decreased for long-term
Table 1 Characteristics of the population of longer-term service users from Merton, 1990-1999 and 2003-2006

\begin{tabular}{lcc} 
& $1990-$ & $2003-$ \\
1999 & 2006 \\
\hline Mean total number & 569 & 728 \\
\hline Mean percentage males & $43 \%$ & $46 \%$ \\
\hline Mean age, years (s.d.) & $43.5(11.4)$ & $42.8(11.8)$ \\
\hline Primary diagnosis & & \\
Schizophrenia/schizoaffective disorder & $55.8 \%$ & $51.6 \%$ \\
Bipolar disorder & $11.4 \%$ & $11.5 \%$ \\
Depression & $16.9 \%$ & $19.3 \%$ \\
Anxiety & $5.6 \%$ & $5.2 \%$ \\
Other & $10.3 \%$ & $12.5 \%$ \\
\hline
\end{tabular}

Table 2 Employment rates in Merton 1990-2006

\begin{tabular}{|c|c|c|c|}
\hline \multirow[b]{3}{*}{ Year } & \multicolumn{3}{|c|}{$\%$} \\
\hline & \multirow[b]{2}{*}{$\begin{array}{l}\text { General employment } \\
\text { rate in Merton }\end{array}$} & \multicolumn{2}{|c|}{$\begin{array}{c}\text { Employment rate among longer-term } \\
\text { service users }\end{array}$} \\
\hline & & All service users & $\begin{array}{l}\text { Diagnosis of } \\
\text { schizophrenia }\end{array}$ \\
\hline 1990 & - & 25.7 & 16.6 \\
\hline 1991 & - & 24.7 & 17.3 \\
\hline 1992 & - & 20.9 & 13.8 \\
\hline 1993 & - & 19.2 & 10.8 \\
\hline 1994 & 76.8 & 14.2 & 9.1 \\
\hline 1995 & 76.2 & 12.5 & 7.5 \\
\hline 1996 & 76.3 & 16.8 & 9.3 \\
\hline 1997 & 77.7 & 14.0 & 9.0 \\
\hline 1998 & 78.9 & 14.8 & 7.9 \\
\hline 1999 & 79.3 & 13.6 & 8.5 \\
\hline 2000 & 73.7 & - & - \\
\hline 2001 & 78.5 & - & - \\
\hline 2002 & 79.1 & - & - \\
\hline 2003 & 77.2 & 10.9 & 7.8 \\
\hline 2004 & 75.8 & 13.7 & 11.2 \\
\hline 2005 & 71.2 & 19.0 & 14.4 \\
\hline 2006 & 74.1 & 20.5 & 15.9 \\
\hline
\end{tabular}

a. Data from the Labour Force Survey were only available from $1994 .{ }^{26}$ b. The cross-sectional survey was not carried out in 2000-2002.

service users with a diagnosis of schizophrenia between 1990 and $1999\left(\chi^{2}=7.17\right.$, d.f. $\left.=1, P<0.01\right)$. The employment rate among this group fell from $16.6 \%$ in 1990 to $8.5 \%$ in 1999, despite the increase in general employment rates during the latter part of this period.

The cross-sectional survey was not carried out between 1999 and 2003. Within this time the employment rate among service users with longer-term mental health problems decreased significantly, from $13.6 \%$ in 1999 down to $10.9 \%$ in $2003\left(\chi^{2}=4.06\right.$, d.f. $\left.=1, P<0.05\right)$. However, for those longer-term service users with a diagnosis of schizophrenia the employment rate only decreased marginally from $8.5 \%$ in 1999 to $7.8 \%$ in $2003\left(\chi^{2}=0.353\right.$, d.f. $\left.=1, P=\mathrm{NS}\right)$. 


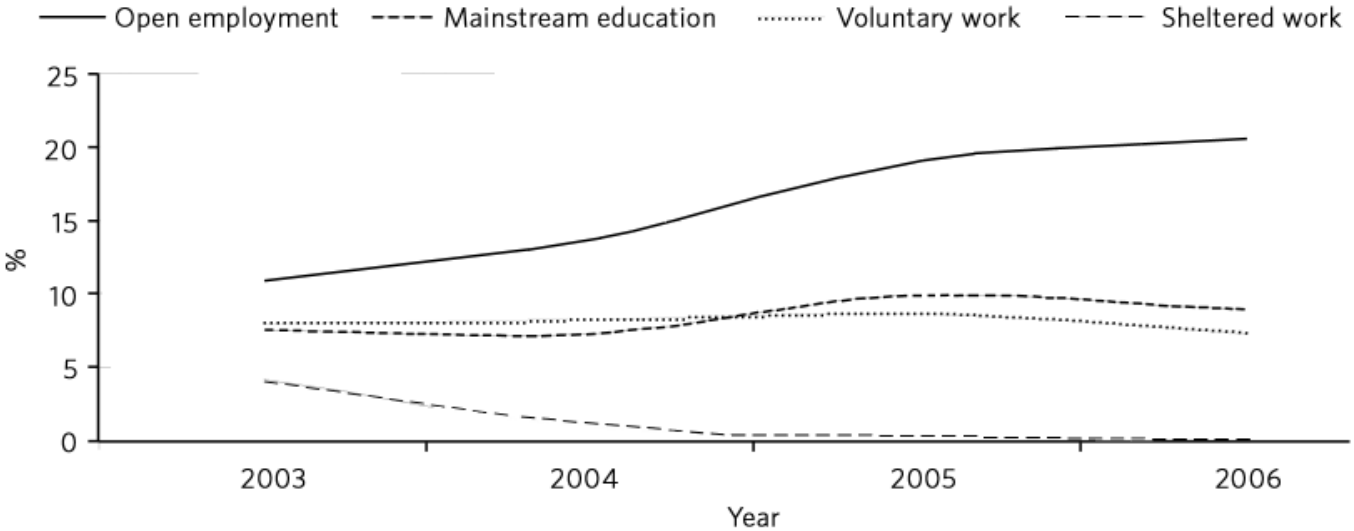

Fig 1 Long-term service users in Merton engaged in work or employment.

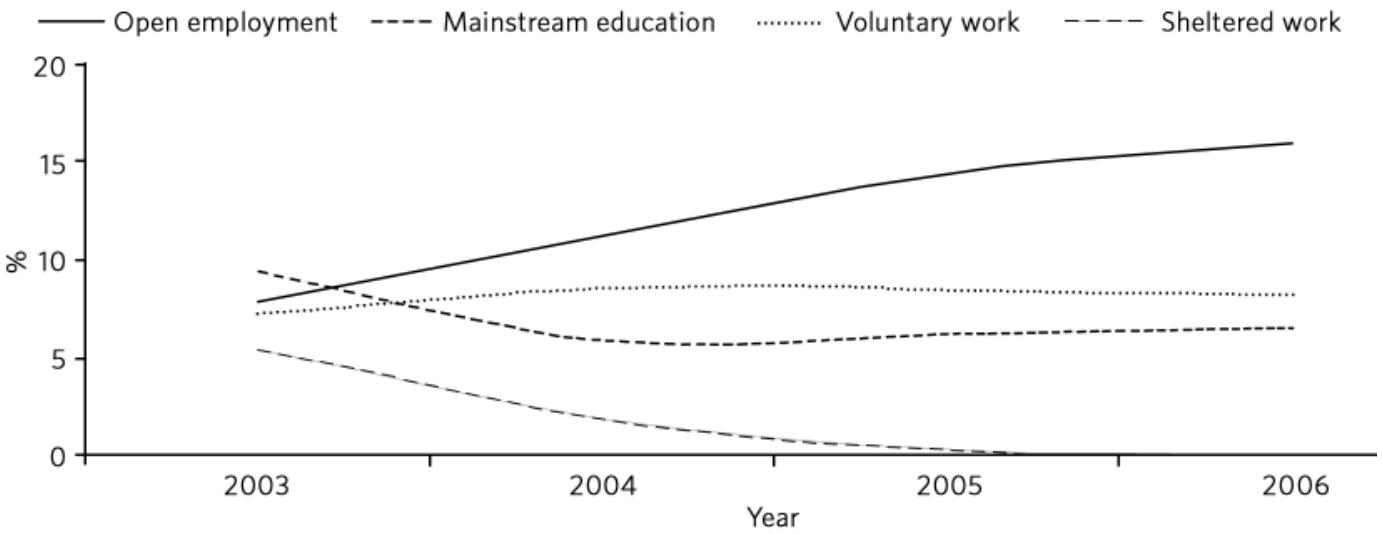

Fig 2 Merton long-term service users with a diagnosis of schizophrenia engaged in work or employment.

In 2004, IPS was implemented into the four CMHTs in Merton; Fig. 1 shows the impact on the employment rates among service users with longer-term mental health problems. In 2003, the employment rate for longer-term service users was $10.9 \%$ and by 2006 this had risen significantly to $20.5 \%\left(\chi^{2}=8.60\right.$, d.f. $\left.=1, P<0.0003\right)$. Figure 2 shows that the same effect was found for longer-term service users with a diagnosis of schizophrenia: in 2003 the employment rate was $7.8 \%$ and this rose to $15.9 \%$ in 2006 $\left(\chi^{2}=10.2\right.$, d.f. $\left.=1, P<0.001\right)$. However, this trend is not found in the general employment rate for Merton: in 2003 the general employment rate was $77.2 \%$ and it decreased for the next 2 years down to $71.2 \%$ in 2005 , before rising again in 2006 to $74.1 \%$.

During the 1990s a sheltered workshop was available to people with mental health problems who lived in Merton along with a variety of pre-vocational schemes to help them gain employment. In 2000 a worker was introduced into the Volunteer Bureau to assist people with mental health problems in taking up volunteering opportunities. In 2003, a day centre closed that provided the funding for the employment specialists in the CMHTs. The sheltered workshop closed in the financial year 2004/05. It is encouraging to note, as Fig. 1 and 2 show, that although the closure of the sheltered workshop resulted in nobody undertaking further sheltered work, the employment rate for people with longer-term mental health problems rose during this period along with the rates for mainstream education and voluntary work.

\section{Service user experience survey}

Overall, 128 service users in Merton responded to the question about whether they had received help with finding work in the past 12 months (Fig. 3): $29 \%$ said they had received help to gain/retain work, which was significantly more than in the National Patient Survey, ${ }^{11}$ where 9\% said they had received help to gain work $\left(\chi^{2}=62.4\right.$, d.f. $=1$, $P<0.001)$. Further, $7 \%$ of service users within the Merton

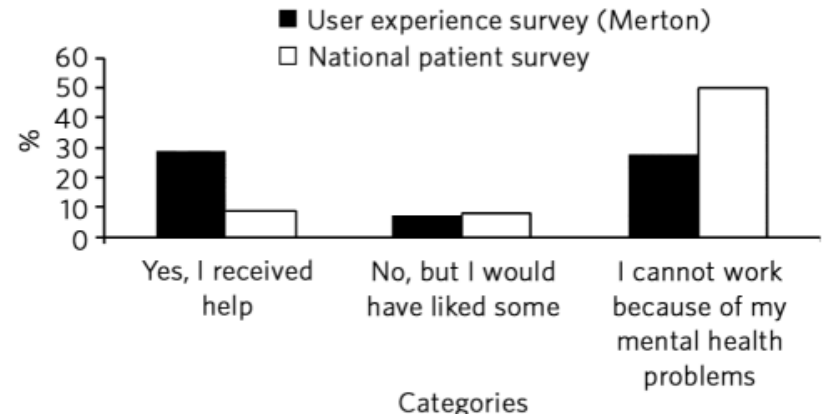

Fig 3 Whether service users had received help with finding work in the past 12-months. 
CMHTs and $8 \%$ in the National Patient Survey ${ }^{11}$ had not received help with finding work but would have liked some $\left(\chi^{2}=0.345\right.$, d.f. $\left.=1, P=\mathrm{NS}\right)$.

However, a significantly lower proportion of service users in Merton (28\%) said they were unable to work because of their mental health problems in comparison with service users in the National Patient Survey (50\%) $\left(\chi^{2}=23.6\right.$, d.f. $=1, P<0.001)$. This would suggest that within the Merton CMHTs, service users had higher expectations about their ability to be able to manage their conditions and gain and retain open employment. Additionally, mental health professionals may have seen open employment as a realistic option for service users and were therefore more actively discussing the possibility of gaining a job and the support that could be offered.

\section{Discussion}

The data presented here clearly show that during the 1990s the proportion of people with longer-term mental health problems in open employment significantly decreased in Merton. This effect is comparable with that found in the neighbouring borough of Wandsworth and the potential reasons for this are likely to be similar. ${ }^{3}$ However, the data for the 4-year period from 2003 to 2006 suggest that implementing high-fidelity IPS appears to have had a significant effect on the employment rates of longer-term service users of secondary mental health services in Merton. It is very encouraging that longer-term service users with a diagnosis of schizophrenia also benefited, with the employment rate significantly increasing from $7.8 \%$ in 2003 to $15.9 \%$ in 2006.

Both the decrease in the employment rates for longerterm service users during the 1990 s and then the increasing employment rates from 2003 onwards did not reflect the general employment rate in Merton in the manner that might have been expected. As general employment rates rose, the employment rates for those with longer-term mental health problems decreased and then vice versa. This is consistent with findings in the UK, where local employment rates for people with a diagnosis of schizophrenia have been found to be independent of the development of the general employment rate. ${ }^{25}$ However, at a macroeconomic level, general labour market conditions as well as economic disincentives affect the likelihood of people with a diagnosis of schizophrenia finding or maintaining a job. ${ }^{26}$ The finding that the employment rate for mental health service users appears to be independent of the general employment rate especially when the latter was decreasing is intriguing. This is contrary to the general belief that vocational outcomes for people with mental health problems worsen during times of general unemployment and seems to suggest that general unemployment is not necessarily a barrier to employment for users of mental health services. The IPS approach is both a focused and targeted intervention and shows what can be achieved when an intervention is targeted irrespective of societal barriers.

Along with significant increases in employment rates, it appears that by implementing high-fidelity IPS within the CMHTs a higher proportion of service users felt able to return to open employment and a greater proportion of service user demand for help to gain/retain open employment was addressed. Service users' expectations of being able to return to work were apparently higher (i.e. a smaller proportion believed they were unable to work because of their mental health problems), suggesting that a higher proportion viewed open employment as a realistic and achievable option. This raises important issues in relation to recovery-focused mental health services.

Implementing IPS involves the integration of an employment specialist into a clinical team. The effect of integrating a person whose expertise is helping people to return to work can challenge care coordinator's own expectations of what service users can achieve in terms of gaining open employment. The literature on client characteristics and vocational success identifies motivation and self-efficacy (wanting a job and believing you can do it) as robust indicators of vocational success ${ }^{27-29}$ and not factors such as diagnosis, severity of symptoms, social skills or level of impairment. ${ }^{30,31}$ From a shared decision-making perspective, ${ }^{32}$ the decision to pursue work should be an active choice based on a clear understanding of what the decision means. Therefore, the challenge for care coordinators, in line with the literature, is not to decide who can and who cannot work but how to support all service users to move forward with life beyond their illness and to help them to identify strategies that they find helpful for managing their conditions as they gain and sustain employment.

\section{Study limitations}

There are some limitations with this study. First, the crosssectional survey from 2003 was carried out for 4 years and although the employment rate trend had been positively reversed, it was still some way off of achieving the employment rates found in 1990. Second, due to a major redesign of Merton adult mental health services in 2007 the cross-sectional survey was not carried out and was replaced by the national Public Service Agreement (PSA) 16 target. $^{33}$ Third, there was no attempt to independently audit care coordinator returns from the cross-sectional survey for accuracy. However, there were no employment targets during the period of the study and so there was no reason for care coordinators to over-report employment status. Fourth, there was a low response rate to the service user survey without additional testing for non-response effects. Even so, this high non-response rate need not necessarily affect the validity of the data collected. Finally, there is no comparison group within this study and it is possible that the changes in employment rates are the result of many factors other than the introduction of IPS or other factors discussed here. However, these changes in employment rates are not echoed anywhere else in England. ${ }^{34}$

In conclusion, this study suggests that at an individual level implementing IPS appears to have a positive effect on service users, with a higher proportion of them feeling able to return to open employment, a smaller proportion believing they were unable to work because of their mental health problems and overall more service users gaining employment. At a CMHT level, it suggests that through implementing IPS mental health professionals may have seen open employment as a realistic option for service users and were therefore more actively discussing the 
possibility of gaining a job and the support that could be offered. At a local labour market level, this study suggests that local employment rates for people with longer-term mental health problems, including those with a diagnosis of schizophrenia, are independent of the development of the general employment rate.

\section{About the authors}

Miles Rinaldi is head of Recovery and Social Inclusion, Springfield University Hospital, London; Tatiana Montibeller is the Lead Employment Specialist in Merton, Rachel Perkins was formerly the Director of Service User Experience and Quality Assurance.

\section{References}

1 Shepherd G. The value of work in the 1980s. Psychiatr Bull 1989; 13: 231-3.

2 Dunn EC, Wewiorski NJ, Rogers SE. The meaning and importance of employment to people in recovery from serious mental illness: results of a qualitative study. Psychiatr Rehabil J 2008; 32: 59-62.

3 Perkins R, Rinaldi M. Unemployment rates among patients with longterm mental health problems. A decade of rising unemployment. Psychiatr Bull 2002; 26: 295-8

4 Thornicroft G, Tansella M, Becker T, Knapp M, Leese M, Schene A, et al. The personal impact of schizophrenia in Europe. Schizophr Res 2004; 69: 125-32.

5 Marwaha S, Johnson S, Bebbington P, Stafford M, Angermeyer MC Brugha $T$, et al. Rates and correlates of employment in people with schizophrenia in the UK, France and Germany. Br J Psychiatry 2007; 191 30-7.

6 Royal College of Psychiatrists. Mental Health and Social Inclusion: Making Psychiatry and Mental Health Services Fit for the 21st Century (Position Statement PS01/2009). Royal College of Psychiatrists, 2009.

7 Social Exclusion Unit. Mental Health and Social Exclusion. Office of the Deputy Prime Minister, 2004.

8 Rinaldi M, Perkins R, Glynn E, Montibeller T, Clenaghan M, Rutheford J. Individual placement and support: from research to practice. Adv Psychiatr Treat 2008; 14: 50-60.

9 Bertram M, Howard L. Employment status and occupational care planning for people using mental health services. Psychiatr Bull 2006; 30: 48-51.

10 Marwaha S, Johnson S, Balachandra S. Clinicians' attitudes to the employment of people with psychosis. Soc Psychiatry Psychiatr Epidemiol 2008; 44: 349-60.

11 Healthcare Commission. National NHS Patient Survey Programme. Survey of Users of Community Mental Health Services 2004-2008. Healthcare Commission, 2008 (http://www.cqc.org.uk/_db/_documents/Full_ 2008_results_with_historical_comparisons.pdf).

12 Crowther R, Marshall M, Bond G, Huxley P. Vocational rehabilitation for people with severe mental illness. Cochrane Database Syst Rev 2001; 2: CD003080

13 Burns T, Catty J, Becker T, Drake RE, Fioritti A, Knapp M, et al. The effectiveness of supported employment for people with severe mental illness: a randomised controlled trial. Lancet 2007; 370: 1146-52.

14 Rinaldi M, Perkins, R. Implementing evidence-based supported employment. Psychiatr Bull 2007; 31: 244-9.
15 Department of Health. Vocational Services for People with Severe Mental Health Problems: Commissioning Guidance. Department of Health, 2006.

16 Department of Health. New Horizons: Towards a Shared Vision for Mental Health - Consultation. Department of Health, 2009.

17 National Institute for Health and Clinical Excellence. Schizophrenia: Core Interventions in the Treatment and Management of Schizophrenia in Primary and Secondary Care (Clinical Guideline 1). NICE, 2002.

18 National Institute for Health and Clinical Excellence. Schizophrenia: Core Interventions in the Treatment and Management of Schizophrenia in Primary and Secondary Care (update). NICE, 2009.

19 Rinaldi M, Perkins R. Comparing employment outcomes for two vocational services: individual placement and support and nonintegrated pre-vocational services in the UK. J Vocational Rehab 2007; 27: 21-7.

20 Rinaldi M, McNeil K, Firn M, Koletsi M, Perkins R, Singh SP. What are the benefits of evidence-based supported employment for patients with first episode psychosis? Psychiatr Bull 2004; 28: 281-4.

21 Rinaldi M, Perkins R, Hickman N, McNeil KM, Singh SP. The Individual Placement and Support approach to vocational rehabilitation for young people with first episode psychosis in the UK. J Ment Health 2010; 19: 483-91.

22 Rinaldi M, Miller L, Perkins R. Implementing the Individual Placement and Support (IPS) approach for people with mental health conditions in England. Int Rev Psychiatry 2010; 22: 163-72.

23 Office for National Statistics. Employment and Unemployment (Jul 2009Jun 2010). Nomis, 2010 (https://www.nomisweb.co.uk/reports/lmp/la/ 2038431888/report.aspx).

24 Office for National Statistics. The Impact of the Recession on the Labour Market. ONS, 2009.

25 Marwaha S, Johnson S. Schizophrenia and employment: a review. Soc Psychiatry Psychiatr Epidemiol 2004; 39: 337-49.

26 Kilian R, Becker T. Macro-economic indicators and labour force participation of people with schizophrenia. J Ment Health 2007; 16: 211-22.

27 Mowbray CT, Bybee D, Harris SN, McCrohan N. Predictors of work status and future work orientation in people with a psychiatric disability. Psychiatr Rehab Bull 1995; 19: 17-28.

28 MacDonald-Wilson K, Rogers ES, Anthony WA. Unique issues in assessing work function among individuals with psychiatric disabilities. J Occup Rehab 2001; 11: 217-32.

29 Tsang H, Lam R, Ng B, Leung O. Predictors of employment outcome for people with psychiatric disabilities: a review of the literature since the mid 80's. J Rehab 2000; 66: 19-31.

30 Bond GR, Resnick SG, Drake RE, Xie H, McHugo GJ, Bebout RR. Does competitive employment improve non-vocational outcomes for people with severe mental illness? J Consult Clin Psychology 2001; 69: 489-501.

31 Catty J, Lissouba P, White $S$, Becker T, Drake RE, Fioritti A et al Predictors of employment for people with severe mental illness: results of an international six-centre randomised controlled trial. Br J Psychiatry 2008; 192: 224-31.

32 O'Connor AM, Wennberg JE, Legare F, Llewellyn-Thomas HA, Moulton BW, Sepucha KR, et al. Toward the 'tipping point': decision aids and informed patient choice. Health Affairs 2007; 26: 716-25.

33 HM Treasury. Meeting the Aspirations of the British People: 2007 PreBudget Report and Comprehensive Spending Review. TSO (The Stationery Office), 2007.

34 Information Centre for Health and Social Care. Mental Health Bulletin Third Report from Mental Health Minimum Dataset (MHMDS) Annual Returns, 2004-2009. Health and Social Care Information Centre, 2008. 